\title{
Systems of donor transfer
}

\author{
Frank Th. de Charro ${ }^{a}$, Hans E.M. Akveld ${ }^{a}$ and Dick J. Hessing ${ }^{b}$ \\ ${ }^{a}$ Centre for Health Policy and Law, Law Faculty, Erasmus University, Rotterdam, \\ Netherlands and ${ }^{b}$ Law Faculty, Leiden University, Leiden, Netherlands
}

Accepted 22 March 1993

\begin{abstract}
Summary
The development of medical knowledge has resulted in a demand in society for donor organs, but the recruitment of donor organs for transplantation is difficult. This paper aims to provide some general insights into the complex interaction processes involved. A laissezfaire policy, in which market forces are relied on, is not acceptable from an ethical and legal point of view in most western European countrics. Especially at the demand side of the exchange of donor organs, commercialism is to be opposed. We judge the use of commercial incentives at the supply side less unacceptable in theory but not feasible in western European countries. Since market forces are deemed unacceptable as instruments for coordinating demand and supply of donor organs, donor procurement has to be considered as a collective good, and therefore governments are faced with the responsibility of making sure that alternative interaction and distribution mechanisms function. The role of organ procurement agencies (OPAs) in societal interaction concerning postmortem organ donation is described using a two-dimensional conceptualisation scheme. Medical aspects of living organ donation are described. An international comparative description of legal systems to regulate living organ donation in western European countries completes this survey.
\end{abstract}

Organ donation; Transplantation; Hospitals

\section{Introduction}

The necessity for the transmission of donor organs results from a need in society to increase the quantity and the quality of life of members of society suffering from end-stage organ failure. The development of medical knowledge has resulted in safe and applicable transplantation technologies. Kidney

Address for correspondence: Dr. F.Th. de Charro, Centre for Health Policy and Law, Law Faculty, Erasmus University, P.O. Box 1738, 3000 DR Rotterdam, Netherlands. 
transplantation spread around the world in the 1960s, as did heart transplantation in the 1980s. Both kidney and heart transplantations are technologies of proven safety, efficacy and acceptable cost-effectiveness relationship. Liver transplantation, pancreas transplantation and several variants of lung transplantation are diffusing too, but on their acceptability consensus is less firmly established.

Since the benefit to the individual patient from a transplant can be substantial, a demand exists for donor organs. The actual demand depends to a large extent on the current state of particular technologies and on the policy-making process guiding the diffusion of transplantation technologies.

Kidney transplantation is a mature technology. Although technological developments, such as new immunosuppressive drugs and better storage solutions, result in improved medical effectiveness, the technology is widely diffused. Gradually it became feasible to transplant kidneys in older patients and in patients with a more complex medical history. The waiting lists for donor kidneys are therefore still growing. In the Netherlands the waiting list for kidney transplantation increased from 648 in 1980 to 1343 in 1990 [1]. Waiting lists for other types of transplantation, such as heart transplants, are also growing.

The formal status of different kinds of transplantation in the Netherlands differs as a consequence of decisions made by the Dutch health authorities. In the 1970s kidney transplantation was included in the standard national health fund provisions. Based on technology assessments of heart [2] and liver [3] transplantation, health authorities decided to include heart and liver transplantation in the reimbursement package [4]. Pancreas and lung transplantations are not yet included in the reimbursement system as a routine treatment.

The recruitment of donor organs for transplantation is difficult. This paper aims to provide some general insights into the complex interaction processes involved. First, a laissez-faire policy is described, in which market forces are relied on. It is argued that for a number of ethical and legal reasons a simple market process is unacceptable in western European countries. Then systems of decision-making on the demand side are analysed. Finally we focus on systems and sub-systems developed to regulate the decisionmaking processes on the supply side of the transfer of donor organs.

\section{Laissez-faire}

Let us, for the sake of argument, explore the option of laissez-faire on the 'organ market'. In this option, donor organs could be offered on a private market at a set price and be sold to buyers who are able to pay the price.

The market mechanism is considered in general to be an efficient mechanism, since it minimises costs of information, guarantees freedom and ensures a high individual involvement. Since utility and profit maximisation are important goals for most individuals, the market system provides a framework in which the advantages to individuals of the availability of 
donor organs can be reflected in a price. Scarcity of donor organs will be reflected in high market prices; this could provide an impetus for individuals to supply those donor organs during life or after death. Once a market price has been set for donor organs, profit-making institutions could step in to carry out the distribution functions involved, such as bridging differences in time and place of supply and demand and organising the intermediate processes involved.

The laissez-faire solution is not completely fiction: it is the reality in some developing countries. Reddy reported that payment for kidneys from nonrelated living donors is not unusual in India [5]. It is not always easy to condemn the selling of organs in situations of scarcity, as was illustrated by Radcliffe's case of a Turkish father selling his kidney to pay for an expensive life-saving operation for his daughter [6]. There is some evidence of the existence of market pressure in some developed countries as well. In the Netherlands public opinion was shocked in 1989 when a commercial agent advertised his reimbursement rates for kidneys [7]. Before condemning this kind of transaction, we should analyse the market forces involved.

In the policy arena, vote maximisation plays a role in determining policy. This seems to induce strong statements about the acceptability of commercial exchange of donor organs and the desirability of legislation prohibiting those activities. In the United States, where commercial freedom is an important value, the Congress adopted the National Organ Transplant Act in 1984, in which commercial markets for organs were outlawed [8]. In the Netherlands, reports about commercial activities immediately provoked a strong reaction by the Secretary of Health. In the proposed Dutch Transplantation Law, commercial transfers of donor organs are forbidden. Commercialisation of donor exchange is seen as immoral and as conflicting with the basic values of the legal system. Although the views of the politicians probably rcflect widely held values, they might also appeal to fundamental psychological factors, prohibiting a rational judgement about the processes involved.

Nevertheless it could be argued that the market system could be used at the supply side of the market [9]. Many are in favour of remuneration or reimbursement of donor organ procurement activities performed in hospitals. An analytical approach has to focus on the demand and supply side of a market for donor organs separately, since the decisions involved are completely different.

\section{Demand side}

Patients searching for a donor organ are willing to pay a certain price for that organ. Some of these patients might be willing to pay from their private means, but an insurance company might also be willing to provide money for a donor organ as part of their coverage. Since a kidney transplant can save substantial health care costs, because dialysis will no longer be necessary, paying for a donor kidney can increase the profits of the insurance company [10]. This willingness to pay can include amounts of money large enough to compensate for supplying a donor organ.

From a consumer point of view, the freedom of the patient to buy or not 
to buy is severely restricted, since the quality of life, or even life itself, of the consumer is conditional on the availability of a donor organ. Purchasing power could therefore be the predominant decision factor in allocating donor organs. This is contrary to the basic right to health care for every citizen, which is incorporated in many western European institutions. In the Netherlands article 22 of the Constitution embodies this provision. Moreover the Constitution guarantees equal access to health care provisions for all citizens. So at the demand side of the theoretical market for donor organs, the allocation has to be made by a non-commercial process of priority setting. Intermediate agents, e.g. hospitals or organ procurement agencies (OPAs), have to ensure that the allocation of donor organs is performed according to the standards set by society.

\section{Supply side}

Once intermediate agencies, whether they be hospitals or OPAs, are involved, the recruitment of donor organs implies decision-making between these intermediate agencies and people willing to make organs available during their life or after death. In principle, every member of society could be an organ donor. For a sub-set of organs, mainly kidneys but also partial livers, donation during life is medically feasible. Decision-making about live donation differs in a fundamental way from decision-making about postmortem organ donation.

The market system is considered inappropriate for allocating donor organs to patients. Therefore other allocation mechanisms have to be used that do not allocate donor organs according to the ability to pay. Those alternative decision-making systems necessarily involve an agency or a complex of agencies responsible for the allocation process.

But perhaps we could use the market mechanism to ensure an optimal supply of donor organs. One might argue that the health risks involved for the donor are prohibitive, but we are negotiating about health risks in many cases. Some occupations imply a health risk, as is the case for a military pilot, and we do not think those jobs unacceptable. In such a case health risks can be reflected in higher wages. An argument against a market system for donor organs could be that a minimum quality standard has to be ensured. But that aspect could easily be enforced by minimum standards, in the same way that we ensure that our food is healthy or our electrical appliances are safe.

\section{Decision-making systems about the allocation of donor organs}

Within western Europe a number of organ procurement agencies exist. Eurotransplant coordinates the decision-making process in the Netherlands, Belgium, Luxembourg, Germany and Austria; UK Transplant coordinates organ procurement in the United Kingdom; France Transplant and the Rhône Méditeranée Services cover France; and, finally, Scandia Transplant coordinates donor procurement in Norway, Sweden and Denmark. These 
non-profit agencies facilitate the international exchange of donor organs in cooperation with the hospitals in which donor organs become available [11]. One important raison d'être of these OPAs is that the medical effectiveness of transplantation increases by matching the similarity in tissue types of recipient and donor organ as closely as possible.

The OPAs play an important role in coordinating the decision-making process in which donor organs are allocated. It is the OPAs' responsibility to apply a system of decision rules in allocating postmortem donor organs to patients on the waiting list. However, donor organs that will become available in transplant centres are sometimes offered first to patients treated in that centre; the remaining donor kidneys are offered to patients on the waiting list of the OPA.

If, in their discussions with the hospital staff and next of kin, patients decide to opt for a living-donor transplant, the OPA will not always be informed, because the patient does not need to be put on the waiting list. An overview of donor kidney flows is given in Fig. 1, which shows that the allocation of donor kidneys is in fact the result of three different systems of decision-making, applying to kidney flow A, B and C.

Living-donor kidneys (flow A) are at present mainly allocated by interaction between the patient, the family and the hospital staff. The medical results of living-donor kidney transplants are better than those of transplantation with postmortem kidneys. Moreover the system of decision-making implies a certain element of chance, since not all patients in need of a transplant are in a position to discuss the possibility of a family transplant. Medical practice differs considerably in western Europe, because of different views on the desirability of using kidneys of related living donors. In the United States the use of donor kidneys from non-related living donors has been advocated [12]. There seems to be a need for guidelines covering institutional responsibilities in allocating those kidneys.

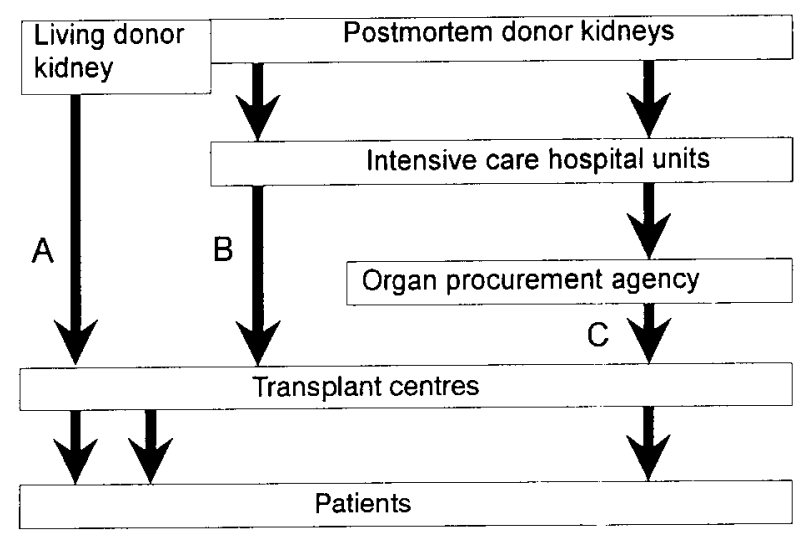

Fig. 1. An overview of donor kidney flows. A: Living-donor kidneys allocated by the hospital staff. B: Postmortem donor kidneys allocated directly by the hospital staff. C: Postmortem donor kidneys allocated by the Organ Procurement Agency in cooperation with the hospital staff. 
The most important flow of kidneys in western European countries concerns postmortem kidneys. The allocation of these kidneys requires a combination of efficiency and equity considerations. Elster [13] reports from the American experience that candidates on the waiting list can get points in a weighting system in three ways:

(i) the number of antigens they share with the kidney that is being allocated;

(ii) sensitisation, i.e. the degree to which they have developed antibodies against other types of kidney;

(iii) the time patients have spent on the waiting list.

The first criterion is an efficiency criterion, since the quality of the match relates positively to higher graft survival. The other two criteria can be classified as equity criteria. It is hardly possible to decide on the mix between efficiency and equity elements in such types of system in an objective way. A typical compromise was put forward by Veatch [14], who proposed a 5050 weighing between those two groups of elements. Because the weighing of efficiency and equity considerations is arbitrary, this in itself is an argument for explicit weighing systems. In that way equal access to transplantation opportunities for patients from different parts of a country, or even a group of countries, could be furthered. But uniformity also can invoke irrational political processes. In western Europe the system for allocating postmortem donor kidneys is discussed within the institutional framework of the OPAs. Within Eurotransplant, guidelines have been developed for allocating donor kidneys. A special sub-system concerns the provision in this set of guidelines that kidneys procured by hospitals in which transplant centres are located do have the authority to allocate $50 \%$ of those kidneys to a sub-list of their own patients. This sub-system of priority setting is pictured in Fig. 1 as flow B.

\section{Decision-making about recruiting donor organs (supply)}

Decision-making about recruiting donor organs is complex. In most countries the main resource of donor organs is the bodies of the deceased, but an important share of donor organs for kidney transplants is provided by living donors. Decision-making about the supply of living-donor organs differs substantially from decision-making in the case of postmortem organ donation. Two important differences are that decisions about living organ donation concern transactions that occur very soon after the decision is made, whereas decision-making about postmortem organ donation is often characterised by a relatively long time between decision and transaction. So in the decision-making process about living organ donation there is a direct link between decision and transaction. Often there is even a direct link between the supplier of the organ and the patient receiving it. These direct links, existing in the case of living organ donation, create a totally different decision environment. 


\subsection{Decision-making about the availability of postmortem organs}

Decision-making about postmortem organ donation is indirect decisionmaking. It is decision-making by people who have a near-zero probability that their own body will be a source of postmortem organ donation. From a population of 15 million in the Netherlands approximately 130000 died in 1990. Of those deaths only 55000 occurred in hospitals [15]. Approximately 1000 of these hospital deaths were cases in which parts of the body could be used as a source of donor organs. So the average probability of any citizen donating organs in 1 year is 66 in 1000000 . Of course if a longer reference period is taken a higher probability results; but even then every person thinking about or deciding on postmortem organ donation is, in a statistical sense, thinking about donation by other people. Direct personal involvement is minimal. This might be an important reason why information and educational campaigns about carrying donor cards are so ineffective.

Decision-making about postmortem organ donation is of course also indirect in another way, since it concerns situations occurring after death. Decisions about events that one will never experience imply, on logical (or psychological) grounds, low involvement. Perception of events after death is of a metaphysical, often religious, character. Fear of dying results in a tendency for many people not to reflect the concrete events that could occur after death.

The characteristics of indirectness and low involvement for decisions about postmortem donation reflect the fact that most people have no personal interest in deciding, on a personal level, about the availability of parts of their remains after death. On the other hand, there is very high stake for patients suffering from terminal organ failure. The benefits are highly valued, because at the societal level health care systems in a devcloped society place high values on increases in the number of life-years and the quality of life.

The decision by most western European governments to ban market forces as instruments for coordinating demand and supply of postmortem donor organs should be complemented by an obvious responsibility on those governments to replace market forces with other policy instruments and coordinating systems. The decision to prohibit the market system changes donor organs from an individual marketable good to a collective good [16]. A collective good is a good that, once it is made available, cannot be individualised by the price mechanism, since the provision in principle benefits everyone. So the cost of production cannot be charged to the individuals who benefit from the availability of that good [17].

Estimates of the potential availability of donor organs indicate that, per million of the population, between 50 and 60 postmortem donor kidneys would be suitable for organ donation [18]. The number of donor hearts and livers can be estimated at about $25 \%$ of that number: between 12.5 and 15 per million. The number of donor lungs in relation to the number of donor kidneys from brain-dead donors is probably even smaller.

We have to be aware of some aspects of the communication process 
surrounding death. Death is not an event that is always marked sharply in time. There is a time span during which the patient is clearly alive and has to be cared for; there is a period during which the state of death has clearly been reached; but in between these periods there is often a time span during which one is uncertain. Therefore every system in which parts of the mortal remains can be used to save lives or to increase the quality of life of patients requires a sub-system to decide on the characteristics of the death state. While non-heart-beating bodies are clearly and objectively in the death state, brain death is a state in which more subtle criteria have to be applied. In the medical community in western countries consensus seems to exist about the general nature of these criteria. Some arguments are being put forward for amending the Uniform Declaration of Death Act, which incorporated proposals by a Harvard Medical School commission about biomedical criteria for the bioethical definition of death [19]. There may also be some discussion about the acceptability of medical actions one would like to perform before death when there is an intention to re-use the organs of a non-heart-beating donor after death [20]. If one allows for those activities, the number of postmortem donor kidneys could be increased by $20-25 \%$.

Having clearly defined criteria for death in the course of events surrounding death, there will be moments during which a patient will still be defined as living, and later on moments during which death is 'actual'. It is important to be aware of the differences in the position of hospital staff, nurses and doctors vis-à-vis the next of kin before and after death. Communication with the next of kin before the death of the patient concerns the activities of the hospital in the interest of the patient. After death the same or other members of the hospital staff have to communicate about the course of events regarding the mortal remains.

All western countries have regulations to ensure that this course of events is restricted to a number of alternative options. The rights of the next of kin concerning the mortal remains are strictly determined by law. If one wants to promote postmortem re-use of donor organs, one is required to activate communication between the next of kin and the hospital staff about the issue. As a consequence of this requirement, hospital staff communication with the next of kin changes from measures in the interest of the still-living person to communication about the destiny of parts of the mortal remains. Before death this communication has to be guided exclusively by concern for the health of the patient. After death the hospital staff (in coordination with the OPA) are concerned with the interests of one or more patients who could be helped by organ donation. Since the next of kin will be grieved by the death of their loved one, communication about the mortal remains will be emotionally burdensome for them.

The legal nature of the communication with the next of kin about the possibility of re-using the organs differs in different countries. In all cases, however, communication in the hours immediately following the patient's death will be overshadowed by complicated and mixed feelings deriving from the death crisis. 
Shortly after death the feelings of the next of kin are often very confused. Images of their dead family member will be foremost in their awareness. Seeing the mortal remains will intensify these images, and the process of parting from their loved one becomes acute. While in a medical sense the mortal remains of the deceased are depersonalised, it is not probable that the next of kin will be in a position to distinguish rationally between the images of the person of their deceased family member and the purely physical remains of him or her. Therefore it must be expected that the communication with the next of kin about re-using organs will almost inevitably be a hardship for them. But every system in which re-using the organs is seriously considered requires this type of difficult and confusing communication. Whatever the exact nature of the legal system involved, this element of confusion cannot be avoided and in our view remains part of the reality of donor recruitment.

Now we will develop a global classification of systems of postmortem donor recruitment. For this classification scheme we use a two-dimensional conceptualisation scheme. One dimension concerns the choice that is made at societal level about the availability of donor organs, varying from collective determinism to an extreme individual point of view. The other dimension concerns the activities organised on a routine basis within the hospital system to promote - or even to guarantee - maximum communication about the option of re-using postmortem organs when medically feasible. An overview of the classification scheme is presented in Table 1.

On the horizontal axis, five systems are distinguished. Which system is operative depends on the transplant law of the country. In a system of collective solidarity, the legal system presupposes that the prohibition of using the market system to ensure adequate supply of donor organs has to be compensated by a legal provision in which all donor organs usable for transplantation are available. Underlying this system is the principle that the decision about the legality of re-using organs has been made a priori. In this system, 'free rider' behaviour is outlawed and the contribution of every citizen is assured. At the other extreme, decision power is completely left to the individual citizens, who, before their death, have to decide on their willingness to make their organs available. As far as we know there is no country where

\section{Table 1}

Systems of decision-making about available postmortem

\begin{tabular}{|c|c|c|c|c|c|}
\hline & $\begin{array}{l}\text { Collective } \\
\text { solidarity }\end{array}$ & $\begin{array}{l}\text { Strict } \\
\text { opting out }\end{array}$ & $\begin{array}{l}\text { Broad } \\
\text { opting out }\end{array}$ & $\begin{array}{l}\text { Broad } \\
\text { opting in }\end{array}$ & $\begin{array}{l}\text { Strict } \\
\text { opting in }\end{array}$ \\
\hline \multicolumn{6}{|c|}{ Hospital organisation } \\
\hline \multicolumn{6}{|c|}{ Legal requirements } \\
\hline \multicolumn{6}{|l|}{ Transplantation } \\
\hline \\
\hline Transplant & & & & & \\
\hline \multicolumn{6}{|l|}{ coordinators } \\
\hline Minimal incentives & & & & & \\
\hline
\end{tabular}


this system is applied in practice. In western European countries and the United States the proportion of people carrying donor cards varies between 10 and $25 \%$ [21-23].

Between the two extremes of complete collective and strict individual predisposition, three other systems are distinguished, in which two systems are characterised by a legal influence on the decision by the next of kin. In a broad opting-in system the next of kin have the authority to 'opt in' where no evidence of a prior decision by the deceased is available. In a broad presumed-consent system the next of kin have the legal authority to refuse the re-use of donor organs of the mortal remains of their late family member. In a strict opting-out system the law permits the re-using of donor organs in all cases where no legal evidence of a decision to opt out is available. In western Europe, Belgium, France and Spain have chosen a presumedconsent system. In Scandinavia the situation is unclear. All those countries opted for a presumed-consent system, but in Sweden the legal basis is in a process of reconsideration. The United Kingdom decided for an opting-in regime. The situation in Germany at the moment is unclear. The Organ Donation Bill for the Netherlands embodies an opting-in system as well.

In the scheme of decision-making systems about postmortem donor organs, the vertical axis concerns the decision-making system in the hospitals. Which system is in force depends on the transplant law of the country and on organisational measures complementing these legal provisions to ensure that the opportunity of organ re-use is considered in the greatest proportion of the relevant cases. Besides a system with minimal incentives, four other options are considered. Transplant coordinators were introduced in many countries during the 1980s [24]. A next step would be to guarantee that in all hospitals where intensive care units are available, an agent is responsible for furthering the consideration of organ procurement in all relevant cases. This could be endorsed by legal obligations on hospitals to appoint such a coordination officer. One step further would be to introduce legal obligations requiring hospitals to request consideration of the option of organ re-use in all relevant cases. An extreme variant of this system has been introduced in the United States [25-29]. This variant - the required request system - was not successful, because it was not specific enough. A legal obligation was introduced to request a decision on organ re-use for all deaths occurring in hospitals. This was considered to be an irrelevant obligation. But more specific legal obligations for hospitals could considerably increase the number of donor organs and complement either a presumed-consent or an opting-in system. In both systems the next of kin have a powerful role. Therefore a policy of ensuring an adequate supply of donor organs has to develop instruments for ensuring that those options are considered seriously.

It is presumed that the actual recruitment of donor organs depends on active implementation of policy instruments with respect to both axes in the classification scheme. So a policy intending to further recruitment of donor organs as much as possible would be characterised by policy measures within a specific framework of legal obligations - according to the upper 
left corner of the diagram. At the other extreme a combination of a strict opting-in system and a hospital sub-system with minimal incentives pictures a society in which policy makers see hardly no interest in transplantation. There is clearly a trade-off between instruments at both axes in the diagram. Collective solidarity systems that are not complemented by an active set of policy measures are inefficient, as are strict opting-in systems that are combined with severe hospital obligations.

\subsection{Decision-making systems about living organ donation}

Decision-making about living organ donation should be viewed as direct decision-making. Most kidneys from a living donor are harvested from family members of the recipient. In those cases the donor knows the recipient of his or her kidney and will live in his or her neighbourhood. The increase in the quality of life resulting from such a family donation will be experienced by the donor. If complications occur as a consequence of the donation of the kidney, the recipient will experience the reductions in quality of life of the donor.

Kidney donation is relatively safe for the donor. A study on 490 donors revealed no mortality and only minor complications [30]. But reliable longterm and large-scale studies of medical records are lacking, and a controlled comparison with non-donors has not been performed [31]. This is a serious lack of information, since animal experiments demonstrated that adverse outcomes resulted after nephrectomy in rats after $40 \%$ of normal life span, which would point to adverse outcomes in humans after approximately thirty years.

The uncertainty about the risks involved in kidney donation for the living donor has led to widely differing practices in western European countrics and the United States. An overview is presented in Table 2. Scandinavian countries - especially Norway - show a high proportion of living-donor kidney transplants, while in the Netherlands the proportion of living-donor kidney transplants is relatively low $[32,33]$.

Since family donation results in a high proportion of HLA-identical or

Table 2

Kidney transplants per million of the population (pmp) and the percentage of living related donations per country, 1990

\begin{tabular}{llc}
\hline Country & Transplants & \% LRD \\
\hline Sweden & 40 & 23 \\
Norway & 48 & 47 \\
Belgium & 40 & 4 \\
Denmark & 29 & 25 \\
Netherlands & 29 & 9 \\
United States & 40 & 20
\end{tabular}


nearly identical donors, the medical results for the donor are better than in the case of postmortem donors [34]. This raises the question of how the interests of the donor must be weighed against those of the recipient. The conflicting interests involved do indicate a necessity for legal deliberations and perhaps even for formal regulations on the conditions under which living organ donation can be considered justifiable.

In Denmark the legislature was aware of the complications already mentioned. In 1966 it was made explicit that 'nevertheless, it must be desirable to establish the legality of this practice and the conditions under which it can take place, in a law.' Twenty-four years later authorities in the Netherlands took the same stand in a policy document on the draft Organ Donation Bill [35]. In this document legislation is thought to be necessary to formalise an acceptable balance between the need to protect the interests of the living donor and the interests of the recipient of the donor organ involved. The Dutch legislature decided that the subject should not be left to the supplying and receiving parties involved in the donor transaction. Neither was it thought acceptable to leave the judgement on the balance of interests to physicians treating the patients.

Organ and tissue removal might involve a risk to the donor. The extent of this risk of damage may vary depending on the kind of organ donation. The risk is smaller, for example, in the case of a bone marrow donation than donation of a kidney or part of the liver. It can be questioned whether the law has to formulate explicitly and in detail under which conditions a variety of organs and tissues might be removed. Refraining from explicit criteria could be considered as a carte blanche. On the other hand, detailed regulation can be a barrier for unforeseen developments and result in rigidity. Legal guidelines of a more general nature, therefore, might be appropriate. Even then there are several alternatives to consider.

The Swedish and the Belgian legislation do not permit living organ donation if serious risks to the donor's health are expected. The Norwegian and the Danish legislation are more tolerant in this respect and only forbid living organ donation where direct danger to the donor arises. In the Netherlands the Organ Donation Bill permits living organ removal even where permanent negative health consequences for the donor might occur. But those living organ donations are limited to cases where the recipient's life is in danger and as a last resort if other treatment options are not available.

Transplantation of kidneys from living donors might solve the shortage of donor organs for kidney transplantation to a large extent. The issue of using kidneys from non-related living donors is at present being discussed [36]. It has been demonstrated that graft survival of kidneys mismatched for both haplotypes is superior to that of postmortem donor kidneys [37].

Living organ donation systems are capable of generating a substantial number of donor kidneys. Living organ donation by family members or friends is only possible in systems in which dependence between donor and recipient exists. The judgement about the acceptability of this interdependence determines the acceptability of the systems. The success of living organ donation in some countries certainly deserves attention. 


\section{Conclusion}

Since market forces are deemed unacceptable as instruments for coordinating demand and supply of donor organs, donor procurement should be considered a public good, and governments are faced with the responsibility of making sure that alternative interaction and distribution mechanisms function. The interests of the patients waiting for a transplant require that the effectiveness of the wide variety of solutions for donor organ recruitment and exchange be the subject of continuing international research.

\section{References}

1 Cohen, B., Persijn, G., (Eds.) Eurotransplant Foundation Annual Report 1991, Leiden, 1991, pp. 23.

2 van Hout, B.A., Bonsel, G., Habbema, D., van der Maas, P.J. and de Charro, F.T., Heart transplantation in the Netherlands: costs, effects and scenarios. Journal of Health Economics, 12 (1993) 73-90.

3 Bonsel, G.J., Essink-Bot, M.L., de Charro, F.T., van der Maas, P.J. and Habbema, J.D.F., Orthotopic liver transplantation in the Netherlands: the results and the impact of a medical technology assessment, Health Policy, 16 (1990) 147-161.

4 de Charro, F.T., Country report: the Netherlands. In M.A. Bos (Ed.), The Diffusion of Heart and Liver Transplantation Across Europe, King's Fund Centre for Health Services Development, London, 1991, pp. 107-113.

5 Reddy, K.C., Organ donation for consideration: an Indian viewpoint. In W. Land, J.B. Dossetor (Eds.), Organ Replacement Therapy: Ethics, Justice, Commerce, Springer-Verlag, Berlin, 1991, pp. 173-180.

6 Radcliffe Richards, J., From him that hath not. In W. Land and J.B. Dossetor (Eds.), Organ Replacement Therapy: Ethics, Justice, Commerce, Springer-Verlag, Berlin, 1991, pp. 190-196.

7 Vrouw Krijgt geld voor haar nier. In Nieuwe Rotterdamse Courant Handelsblad. 16 September, 1989.

8 Hansmann, H., The economics and ethics of markets for human organs, Journal of Health Politics, Policy and Law, 14 (1989) 57-85.

9 Wight, J.P., Ethics, commerce, and kidneys, British Medical Journal 303 (1991) 110.

10 de Charro, F.T., Kosten-effectiviteitsanalyse van het nierfunktievervagingsprogramma in Nederland, Eburon, Delft, 1988.

11 Wight, C., Transplant coordinators and organ procurement in western Europe, Journal of Transplant Coordination, 1 (1991) 39-41.

12 Spital, A., Unconventional living kidney donors: attitudes and use among transplant centers, Transplantation, 48 (1989) 243-248.

13 Elster, J., Ethical issues in organ transplantation (lecture at Harvard University, 15 November 1990).

14 Veath, R.M., Who empowers medical doctors to make allocative decisions for dialysis and organ transplantation? In W. Lad and J.B. Dossetor (Eds.), Organ Replacement Therapy: Ethics, Justice, Commerce, Springer-Verlag, Berlin, 1991, pp. 331-336.

15 Central Office of Statistics, den Haag.

16 de Charro, F.T., Akveld, J.E.M. and Hessing, D.J., Donor recruitment: individual rights on health care and the feasibility of a presumed consent and a required request system. In W. Land and J.B. Dossetor (Eds.), Organ Replacement Therapy: Ethics, Justice, Commerce, Springer-Verlag, Berlin, 1991, pp. 284-286.

17 Lipsey, R.G., Steiner, P.O. and Purvis, D.D., Economics, 8th edn., Harper and Row, New York, 1987, p. 415.

18 Bergström, C. and Gäbel, H., Organ donation and organ retrieval programs in Sweden, 1990, Journal of Transplant Coordination, 1 (1991) 47-51. 
19 Sass, H.-M., Philosophical arguments in accepting brain death criteria. In W. Land and J.B. Dossetor (Eds.), Organ Replacement Therapy: Ethics, Justice, Commerce, Springer-Verlag, Berlin, 1991, pp. 249-253.

20 Kootstra, G., Wijnen, R., van Hooff, J.P. and van der Linden, C.J., Twenty percent more kidneys through a non-heart-beating program, Transplantation Proceedings, 23 (1991) 910-911.

21 Hessing, D.J., de Charro, F.T, and Akkermans, P.W.C., Psychological aspects of organ procurement systems. In W. Land and J.B. Dossetor (Eds.), Organ Replacement Therapy: Ethics, Justice, Commerce, Springer-Verlag, Berlin, 1991, pp. 287-290.

22 Evans, R.W. and Manninen, D.L., US public opinion concerning the procurement and distribution of donor organs, Transplantation Proceedings, 20 (1988) 781-785.

23 Gåbel, H. and Lindskoug, K., A survey of public attitudes toward cadaveric organ donation in a Swedish community, Transplantation Proceedings, 20 (1988) 431.

24 van der Vliet, J.A., Cohen, B., Vroemen, J.P.A.M., Ruers, T.J.M. and Kootstra, G., Successful reorganization of organ procurement in the Netherlands, Transplantation Proceedings, 16 (1984) 191-192.

25 Caplan, A.L., Ethical and policy issues in the procurement of cadaver organs for transplantation, New England Journal of Medicine, 311 (1984) 981-983.

26 Prottas, J.M., Shifting responsibilities in organ procurement: a plan for routine referral, Journal of the American Medical Association, 260 (1988) 832-833.

27 Annas, G.J., The paradoxes of organ transplantation, American Journal of Health Policy, 78 (1988) 621-622.

28 Thrukral, V.K., Required request laws: are they adequate? Paper presented at Tulane Symposium on Organ Donation, 1989.

29 Hessing, D.J., Elffers, H. and de Charro, E.T., The legislation of organ donation, Paper presented at 2nd European Conference on Law and Psychology, Nürnberg, September 1990.

30 Karlberg, H.I., Norden, G., Brynger, H. and Blohme, I., The living donor in kidney transplantation: the Gothenburg experience (1965-1990) from 490 consecutive donor nephrectomies. In W. Land and J.B. Dossetor (Eds.), Organ Replacement Therapy: Ethics, Justice, Commerce, Springer-Verlag, Berlin, 1991, pp. 50-53.

31 Bertolatus, J.A., Renal transplantation for the nephrologist: living donor kidney transplantation: what did we learn during the 1980s? what should we learn during the 1990s? American Journal of Kidney Diseases, 17 (1991) 596-599.

32 Bos, M.A. and Wilmink, J.M., Attitudes to living related kidney donors in the Netherlands. In W. Land and J.B. Dossetor (Eds.), Organ Replacement Therapy: Ethics, Justice, Commerce, SpringerVerlag, Berlin, 1991, pp. 40-43.

33 Geerlings, W., Tufveson, G., Ehrich, J.J.H. et al., Combined report on regular dialysis and transplantation in Europe, 21, 1990, Nephrology, Dialysis and Transplantation, 6, Suppl. 4 (1991).

34 Gjertson, D.W., Terasaki, P.I., Takemoto, S. and Mickey, M.R., National allocation of cadaveric kidneys by HLA matching: projected effects on outcome and costs, New England Journal of Medicine, 324 (1991) 1032-1036.

35 Parliamentary documents, II, 1991-1992, 22358 Nos. 1-3.

36 Spital, A., Unconventional living kidney donors: attitudes and use among transplant centers, Transplantation, 48 (1989) 243-248.

37 Sutherland, D.E.R., Bently, F.R., Sanders, J. et al., Renal allograft functional survival are similar for kidneys from sibling donors mismatched for one versus two haplotypes with the recipient, Transplantation Proceedings, 17 (1985) 110-112. 